Supplemental Information

\title{
Facile method for determining the aspect ratios of mineral dust aerosol by electron microscopy
}

\author{
Daniel P. Veghte and Miriam Arak Freedman \\ Department of Chemistry, The Pennsylvania State University, University Park, Pennsylvania
}

\section{Summary}

This supplemental information shows additional figures of the dependence of the measured aspect ratios on particle size. Only submicron particles were used to determine the aspect ratios reported in the manuscript.
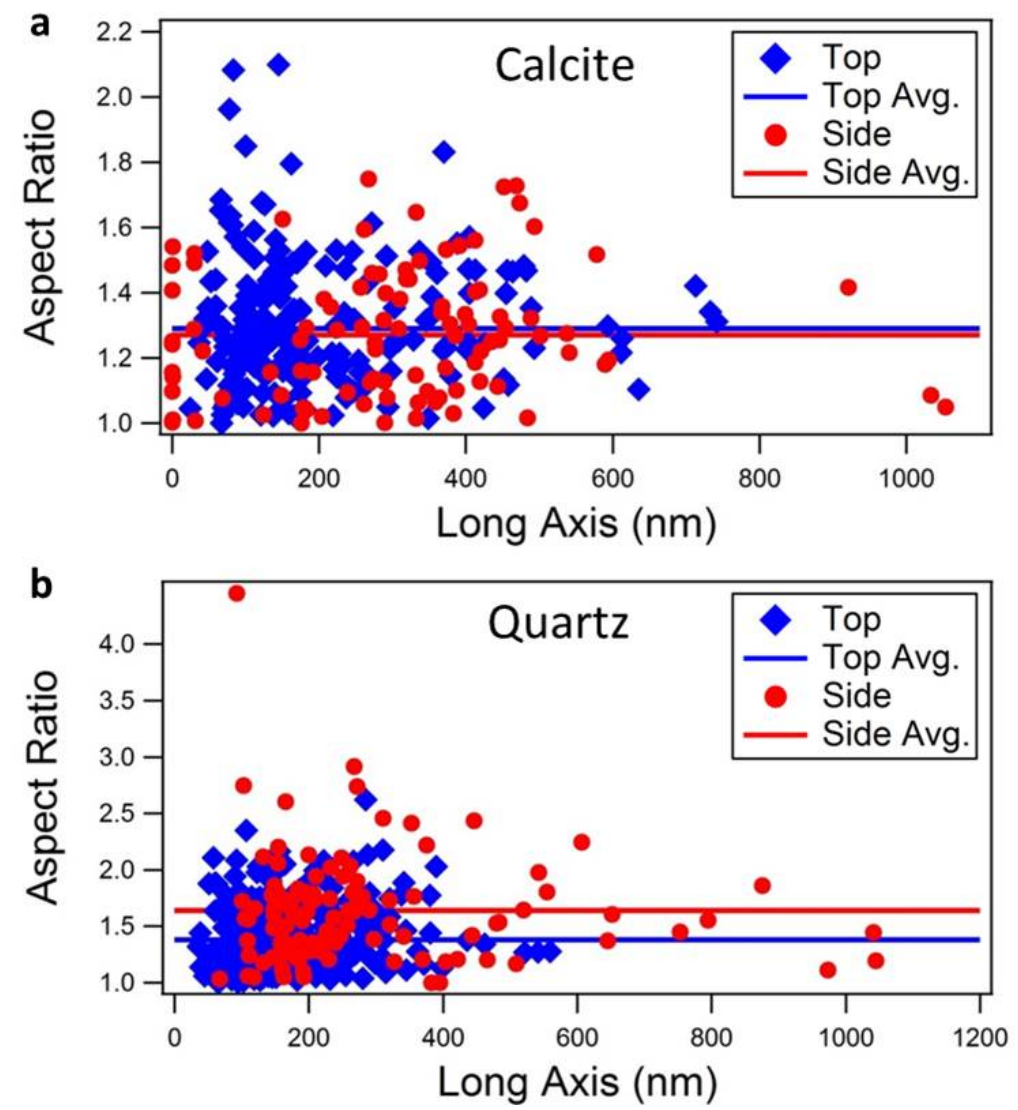

Figure S1. The aspect ratio as a function of the length of the longer of the two measured axes in the top-down and side-on orientations for a) calcite and b) quartz. The points are individual measurements and the line denotes the average aspect ratio for the submicron particles as reported in Table 1. 

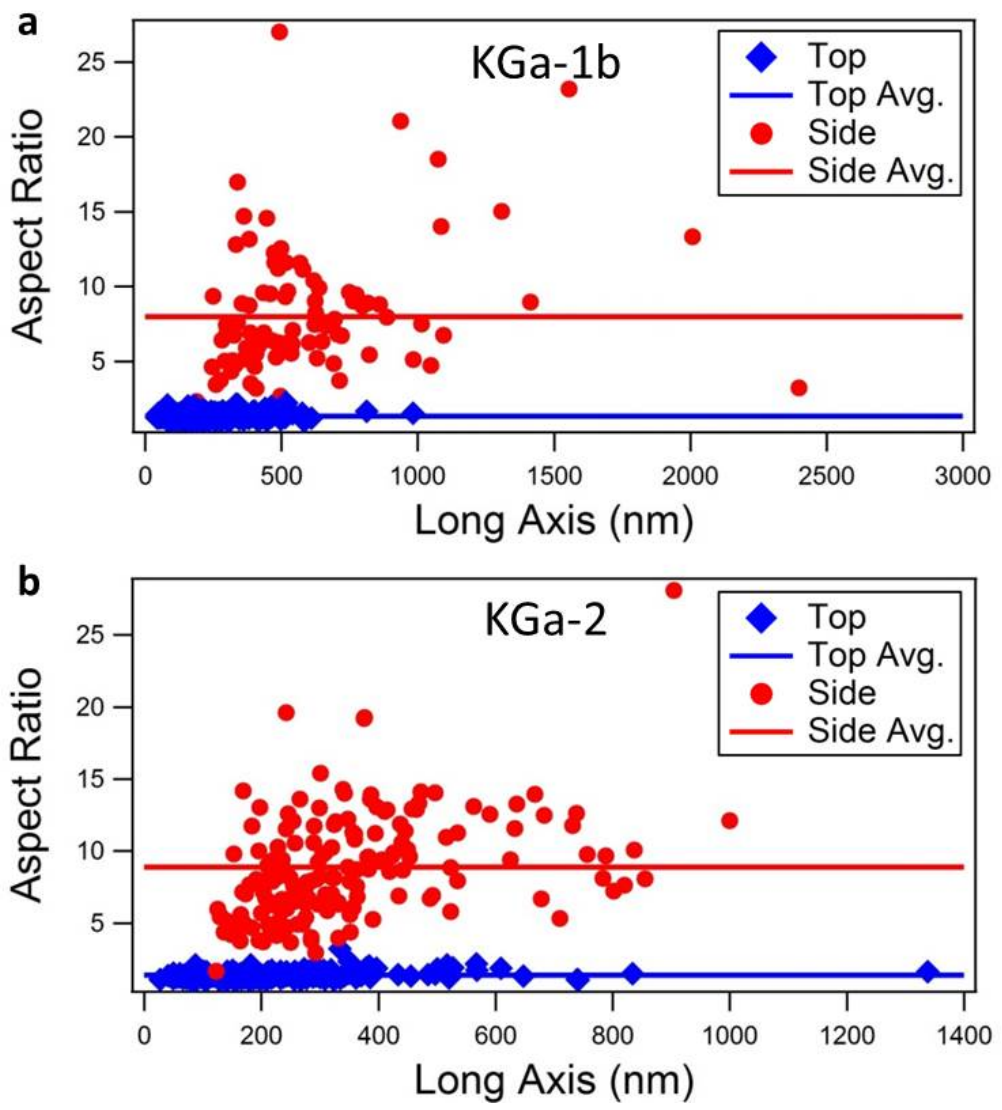

Figure S2. The aspect ratio of kaolinite as a function of the length of the longer of the two measured axes in the top-down and side-on orientations for a) KGa-1b and b) KGa-2. The points are individual measurements and the line denotes the average aspect ratio for the submicron particles as reported in Table 1. 

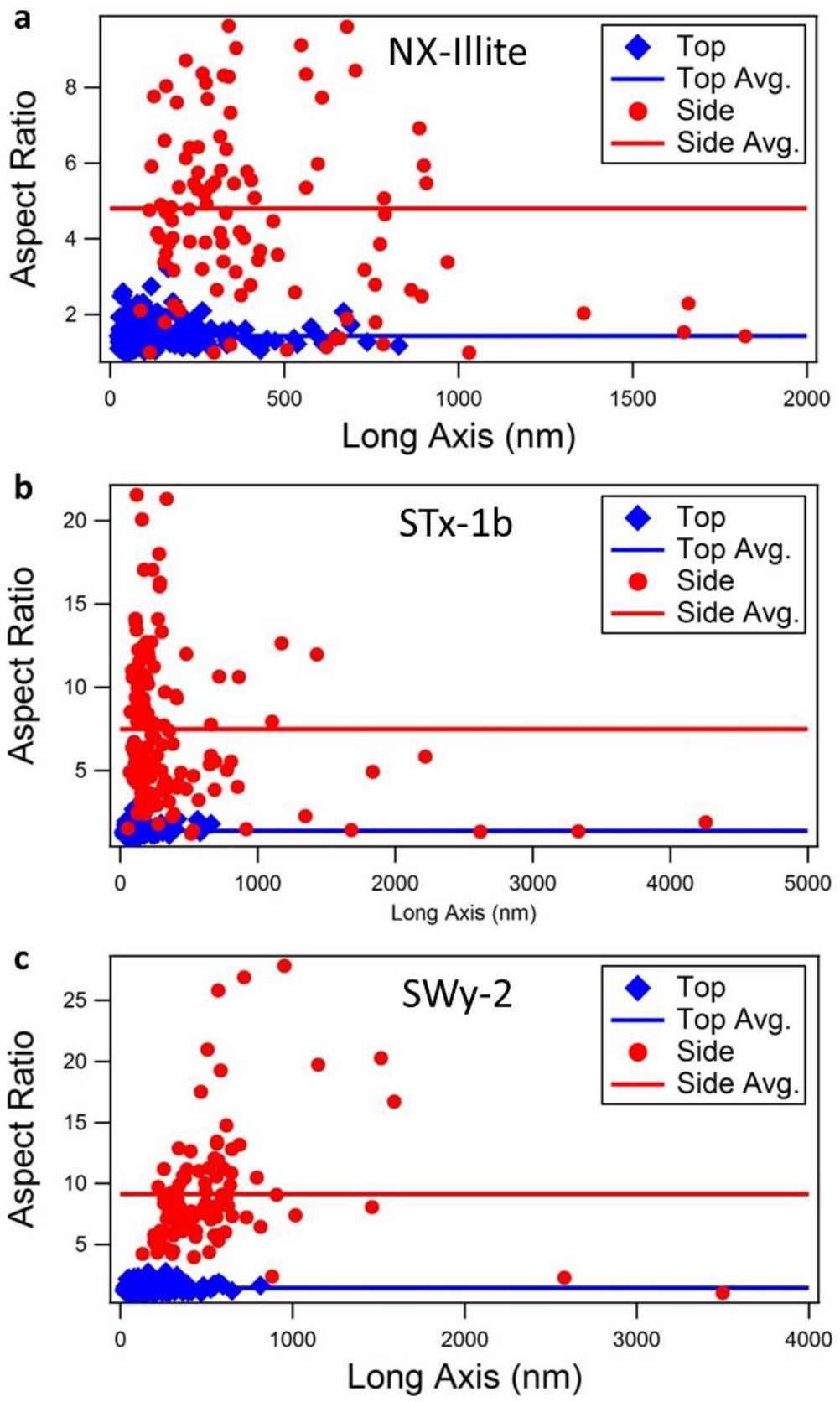

Figure S3. The aspect ratio as a function of the length of the longer of the two measured axes in the top-down and side-on orientations for a) NX-illite, b) STx-1b montmorillonite, and c) SWy-2 montmorillonite. The points are individual measurements and the line denotes the average aspect ratio for the submicron particles as reported in Table 1. 